\title{
Correspondence
}

\section{Jet ventilation in management of the difficult airway}

When the patient's lungs cannot be ventilated or the trachea intubated, and spontaneous ventilation is not likely to return, options include tracheostomy, cricothyroidotomy, transtracheal insufflation of oxygen, and transtracheal jet ventilation. ${ }^{1}$ Although mask ventilation may be difficult or impossible, direct laryngoscopy often establishes an airway, even when tracheal intubation or visualization of the glottic opening cannot be accomplished. A patent airway may be present when the laryngoscope blade is in place, but a source of positive pressure is still required. In this situation, I propose that supraglottic jet ventilation ${ }^{2,3}$ be considered as a means of ventilation. I envision that the injector would be directed away from the mucosa along the airway created by passage of the laryngoscope blade (Figure). Even with limited ventilation, oxygen delivery should be sufficient to permit more controlled and complex efforts at tracheal intubation, a more controlled surgical access to the airway, or the return of consciousness. A number of complications are associated with jet ventilation, regardless of route, although

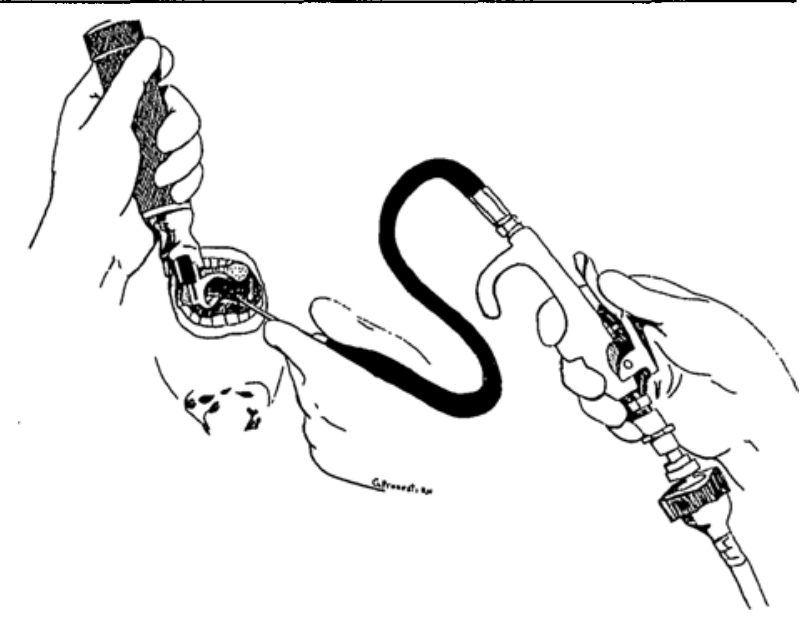

FIGURE Use of supraglottic jet ventilation to provide ventilation in an airway established by the presence of the laryngoscope blade. Once the blade is positioned, the laryngoscopist directs the injector from the jet ventilation apparatus along that airway, keeping the tip of the injector away from the pharyngeal mucosa. An assistant controls the delivery of each breath with the valve on the jet ventilation apparatus. airway obstruction which persists after direct laryngoscopy and repositioning of the laryngoscope is certainly the greatest barrier to the successful use of supraglottic jet ventilation in the difficult airway. However, clinical ${ }^{4}$ and laboratory ${ }^{5}$ experience indicates that considerable obstruction must be present before jet ventilation is ineffective. Although this use of jet ventilation remains to be tested the ability to provide ventilation in the face of considerable obstruction suggests that it may be valuable in some emergencies.

Allan Gottschalk MD, PhD

Philadelphia, USA

\section{REFERENCES}

1 Benumof JL. Management of the difficult adult airway. With special emphasis on awake tracheal intubation. Anesthesiology 1991; 75: 1087-110.

2 Oulton $J L$, Donald DM. A ventilating laryngoscope. Anesthesiology 1971; 35: 540-2.

3 D'Alessio JG. The Bullard laryngoscope as jet ventilator (Letter). Anesth Analg 1995; 81: 435.

4 Koufman JA, Little FB, Weeks DB. Proximal large-bore jet ventilation for laryngeal laser surgery. Arch Otolaryngol Head Neck Surg 1987; 113: 314-20.

5 Ward KR, Menegazzi J, Yealy DM, Klain MM, Molner $R L$, Goode JS. Translaryngeal jet ventilation and end-tidal $\mathrm{PCO}_{2}$ monitoring during varying degrees of upper airway obstruction. Ann Emerg Med 1991; 20: 1193-7.

\section{Inserting Double-Lumen tubes}

I was very interested to read the letter of Panadero, Iribarren, Ferdandez-Liesa and Monedero entitled "A simple method to decrease malposition of Robertshawtype tubes" (Can J Anaesth 199643 ; 984). The use of a partially inflated bronchial cuff on a left double-lumen tube to prevent it entering too deeply is logical but incomplete. If the bronchial cuff is inflated in the trachea, just below the cricoid, until there is almost a seal in the trachea and then advancing the DLT while regularly inflating the lungs can identify the exact moment when the bronchial cuff plugs the entrance to the left main bronchus. Four characteristics identify the point of transition. Inflation of both lungs becomes inflation of only the left lung. This can be detected by inspection and by auscultation. In addition, the compliance of the 